\title{
UTILIDADE DA INFORMAÇÃO CONTÁBIL GERENCIAL NA GESTÃO DAS MICRO E PEQUENAS EMPRESAS: UM ESTUDO COM EMPRESAS DO PROGRAMA EMPREENDER DE UBERLÂNDIA - MG
}

DOI: 1014211/Rege.33235

Artigo recebido: 02/01/2015

Artigo aprovado em:18/09/2015

Lara Fabiana Morais Borges - Universidade Federal de Uberlândia - UFU ${ }^{1}$ Edvalda Araújo Leal - Universidade Federal de Uberlândia - UFU ${ }^{2}$

Resumo: O objetivo deste estudo é analisar qual a importância atribuída pelos gestores de MPEs às informações contábeis gerenciais e identificar a periodicidade de uso destas. Esta pesquisa classifica-se como mista por utilizar métodos qualitativos e quantitativos para atingir o objetivo proposto. A amostra foi composta por 75 gestores de micro e pequenas empresas vinculadas ao Programa Empreender desenvolvido pela Associação Comercial e Industrial de Uberlândia (ACIUB). Como metodologia, utilizou-se a análise de conteúdo (para fase qualitativa), seguida pela análise descritiva e pelo teste de comparações múltiplas de proporções (fase quantitativa). Como resultados, verificou-se que os gestores avaliam as informações contábeis gerenciais como "muito importante", porém, na maioria das vezes, não as implementam por falta de conhecimento. Sobre a frequência de utilização, a maioria das ferramentas apresentadas foi considerada como "muito utilizadas", sendo que não foi possível avaliar a periodicidade formal de utilização. Os resultados do teste estatístico de comparações múltiplas de proporção evidenciaram que na maioria das ferramentas de controles gerenciais há uma diferença de proporção entre as proporções de "muito importante" e "pouco importante". Os resultados evidenciam que os gestores consideram as informações contábeis gerenciais de alta importância e as utilizam com grande frequência, divergindo dos encontrados na literatura pesquisada.

Palavras-chave: gestores; pequenas empresas; informações contábeis gerenciais.

\section{UTILITY OF ACCOUNTING INFORMATION IN MICRO AND SMALL BUSINESS MANAGEMENT: A STUDY WITH ORGANIZATIONS IN THE PROGRAMA EMPREENDER FROM UBERLÂNDIA - MG}

\begin{abstract}
This study aims to analyze the importance attributed by MPEs managers to accounting information managerial and identify the periodicity of their use. The research is classified as mixed, once it is used qualitative and quantitative methods

\footnotetext{
${ }^{1}$ E-mail: lara fabiana@hotmail.com

2 Endereço: Âvenida João Naves de Ávila, 2121, Bloco F, Sala 1F253, Campus Santa Mônica, Uberlândia - MG, CEP: 38400-000. E-mail: edvalda@facic.ufu.br
}

BORGES, L. F. M.; LEAL, E. A. Utilidade da informação contábil gerencial na gestão das micro e pequenas empresas: um estudo com empresas do Programa Empreender de Uberlândia - MG. Revista de Empreendedorismo e Gestão de Pequenas Empresas, v.4, n.3, 2015. 
in order to reach the proposed aim. The sample consisted of 75 managers of micro and small companies linked to the "Programa Empreender" developed by the "Associação Comercial e Industrial de Uberlândia - ACIUB" (Industrial and Commercial Association of Uberlândia). In order to evaluate the results of the research, content analysis was used (for the qualitative phase), followed by descriptive analysis and multiple comparisons of proportions test (quantitative phase). Among the findings, it can be highlighted that managers evaluate accounting information managerial as "very important", but most of the times they do not implement them due to the lack of knowledge. About the frequency of use, most of the presented tools were considered highly used, but it was not possible to evaluate the formal periodicity of use. The results of the statistical test for multiple comparisons of proportions showed that in most of the managerial control tools there is a ratio difference between the proportions of "very important" and "not much important". The results showed that managers consider accounting information managerial of highly importance and use them with great frequency, being divergent from what it is found in the literature.

Keywords: managers; small companies; accounting information managerial.

\section{Introdução}

A contabilidade gerencial é focada em atender as necessidades do usuário interno da organização e, para tanto, oferece informações oportunas para o processo decisório (GARRISON; NOREEN; BREWER, 2007). Acredita-se que com informações voltadas a atender tal usuário, o processo decisório seja amparado e se adeque ao modelo de gestão.

Apesar da relevância das Micro e Pequenas Empresas (MPEs) na economia brasileira, responsáveis por $52 \%$ dos empregos diretos do país e $99,1 \%$ da riqueza produzida (SEBRAE, 2013a) estes empreendimentos passam por diversos problemas de gestão. O Serviço Brasileiro de Apoio às Micro e Pequenas Empresas (SEBRAE) constatou por meio de um estudo que 49,9\% das pequenas empresas encerram suas operações com até dois anos e 59,9\% com até quatro anos. Nesse mesmo estudo, a maioria dos respondentes apontou as falhas gerenciais como sendo as causas para tal fato (SEBRAE, 2005). Os altos índices de mortalidade das MPEs estão ligados direta ou indiretamente às falhas no processo de gestão (HUTCHINSON; QUINTAS, 2008).

BORGES, L. F. M.; LEAL, E. A. Utilidade da informação contábil gerencial na gestão das micro e pequenas empresas: um estudo com empresas do Programa Empreender de Uberlândia - MG. Revista de Empreendedorismo e Gestão de Pequenas Empresas, v.4, n.3, 2015. 
Devido à importância destes empreendimentos para a economia nacional e as causas apontadas pelo insucesso de tais negócios, alguns estudos (STROEHER; FREITAS, 2008; FARIA; AZEVEDO; OLIVEIRA, 2012; ALBUQUERQUE et al., 2013) foram delineados na tentativa de verificar qual a utilidade da informação contábil na gestão das MPEs. Os resultados apontam que nas MPEs há uma cultura de que a contabilidade é utilizada somente para atendimento ao fisco e leis trabalhistas. Essas empresas sofrem pressões do mercado devido à alta competitividade e a carga tributária brasileira.

Verificou-se que nas MPEs, os gestores não conhecem as ferramentas de controle para auxiliar a gestão do negócio, possuem dificuldade em separar o patrimônio da entidade e dos proprietários, e a gestão é baseada na experiência do gestor para a tomada de decisões (STROEHER; FREITAS, 2008; FARIA; AZEVEDO; OLIVEIRA, 2012; ALBUQUERQUE et al., 2013).

Assim, tendo em vista as dificuldades enfrentadas pelos gestores das MPEs no gerenciamento de seus negócios e o objetivo da contabilidade gerencial em fornecer informações que sejam adequadas ao modelo decisório das organizações (FERNANDES; KLANN; FIQUEREDO, 2011), o objetivo geral que norteia a presente pesquisa é analisar qual a importância atribuída pelos gestores de MPE às informações contábeis gerenciais e identificar a periodicidade de uso delas. $\mathrm{O}$ público-alvo da pesquisa são os gestores participantes do Programa Empreender da cidade de Uberlândia-MG. Espera-se que o presente estudo contribua com gestores de MPEs ao mostrar-Ihes a importância da utilização das informações contábeis gerenciais para a gestão do negócio.

Segundo Alves et al. (2013), as MPEs devem ser estudadas pelas diferenças apresentadas por estes empreendimentos, pela forma simples e características peculiares dessas empresas. Savioz e Blum (2002) abordam que a estrutura simples das empresas de menor porte influencia na maior cooperação interna entre os indivíduos e melhor comunicação se comparadas às empresas de grande porte, o que favorece o estabelecimento de uma rede de contatos interna e externa, tornando-se um fator positivo para a gestão destas organizações.

BORGES, L. F. M.; LEAL, E. A. Utilidade da informação contábil gerencial na gestão das micro e pequenas empresas: um estudo com empresas do Programa Empreender de Uberlândia - MG. Revista de Empreendedorismo e Gestão de Pequenas Empresas, v.4, n.3, 2015. 
A estrutura do estudo compreende cinco seções. Nesta primeira, consta a introdução, em que foi caracterizado o problema, o objetivo e a justificativa para este trabalho. Em seguida, é feita a revisão da literatura, que dá embasamento teórico ao estudo, com ênfase na gestão de MPE e nas informações contábeis gerenciais. Na sequência, apresenta-se a metodologia adotada, seguida da exposição dos resultados obtidos e sua análise. Por fim, apresenta-se as considerações finais do estudo e as referências utilizadas.

\section{Caracterização das micro e pequenas empresas}

As MPEs representam 99\% dos estabelecimentos empresariais do país, sendo importantes para a economia brasileira (SEBRAE, 2013a). De acordo com o Direcionamento Estratégico do Sebrae, que faz uma projeção para 2022, estas organizações representam $20 \%$ do Produto Interno Bruto (PIB), $40 \%$ no total de salários e ainda correspondem por $28 \%$ dos faturamentos das empresas.

Em um estudo do Sebrae sobre a sobrevivência das MPEs no Brasil (divulgado em julho de 2013), observou-se que dentre as empresas que iniciaram suas atividades em 2007 até o fim de 2010, mais de 70\% destes empreendimentos se mantiveram no mercado. Alguns estados estiveram acima da média nacional: em Minas Gerais, Paraíba e Distrito Federal, 80\% dos empreendimentos se mantiveram no mercado durante estes anos (SEBRAE, 2013c).

Ainda de acordo com o mesmo estudo, houve uma redução da taxa de mortalidade para empresas com até dois anos de atuação em 2005: a taxa era de $49,9 \%$ e caiu para 30\% conforme pesquisa realizada até 2010 . Segundo o Sebrae (2013c), esse fato ocorreu devido a ajustes na legislação que favoreceram as pequenas empresas, o aumento de escolaridade dos gestores e melhorias ocorridas no mercado.

Apesar da taxa de mortalidade das MPEs ter reduzido em quase $20 \%$, o número de empresas que encerram as suas atividades nos primeiros anos ainda é alto: 24,4\% (SEBRAE, 2013c). Em estudo desenvolvido pelo Sebrae (2005), os gestores apontaram que as principais fatores que contribuem para o encerramento

BORGES, L. F. M.; LEAL, E. A. Utilidade da informação contábil gerencial na gestão das micro e pequenas empresas: um estudo com empresas do Programa Empreender de Uberlândia - MG. Revista de Empreendedorismo e Gestão de Pequenas Empresas, v.4, n.3, 2015. 
das atividades são: falta de capital, falta de clientes combinada com inadimplência, problemas de planejamento e gestão. A falta de planejamento é um dos aspectos que contribui para a alta mortalidade das pequenas empresas, sendo que os estudos de Sandberg, Robinson e Pearce II (2001) e Huang (2009) também apontam este fato.

Para Alves et al. (2013), outros fatores que contribuem para esse fato é a alta concorrência, excessiva carga tributária, despreparo dos empreendedores e o pouco ou não uso de mecanismos de controle gerencial. Vogel e Wood Junior (2012) complementam que as MPEs possuem como características, a informalidade nos processos organizacionais, acúmulo de funções e a centralização de decisões.

No Brasil, as MPEs podem ser classificadas de acordo com vários critérios definidos por diferentes órgãos: Receita Federal do Brasil (RFB), Banco Nacional de Desenvolvimento Econômico e Social (BNDES), Lei Complementar 139/2011 e Sebrae. Cada um destes órgãos utiliza uma forma para classificar as MPEs. A Lei Complementar 139/2011 trata da classificação das MPEs, bem como das formas de tributação disponíveis a tal modalidade de empreendimentos.

No Quadro 1 a seguir, são apresentadas as formas de classificação adotadas pelo Sebrae e pela Lei 139/2011.

Quadro 1 - Exemplos de classificações de MPE

\begin{tabular}{|l|l|l|l|}
\hline \multicolumn{3}{|c|}{ Sebrae } & \multicolumn{1}{c|}{ Lei 139/2011 } \\
\hline Porte/Setor & Indústria & $\begin{array}{c}\text { Comércio e } \\
\text { Serviços }\end{array}$ & \multicolumn{1}{c|}{ Faturamento anual } \\
\hline Microempresas & Até 19 & Até 9 & Igual ou inferior a $\mathrm{R} \$ 360.000$ \\
\hline $\begin{array}{l}\text { Pequenas } \\
\text { empresas }\end{array}$ & De 20 a & De 10 a 49 & $\begin{array}{l}\text { Acima de } \mathrm{R} \$ 360.000,00 \text { até } \mathrm{R} \$ \\
3.600 .000,00\end{array}$ \\
\hline
\end{tabular}

Fonte: Adaptado de SEBRAE (2013b) e Lei Complementar 139/2011

Pela classificação do Sebrae, as empresas são divididas pelo setor de atuação: indústria ou comércio. De acordo com o número de funcionários, é definido o porte. No caso dos outros órgãos, RFB e Bndes, as MPEs são classificadas de acordo com o faturamento anual auferido. Na presente pesquisa adotou-se os critérios do Sebrae e da Lei 139/2011.

BORGES, L. F. M.; LEAL, E. A. Utilidade da informação contábil gerencial na gestão das micro e pequenas empresas: um estudo com empresas do Programa Empreender de Uberlândia - MG. Revista de Empreendedorismo e Gestão de Pequenas Empresas, v.4, n.3, 2015. 
No próximo tópico apresentam-se os estudos correlatos que investigaram nas MPEs a utilidade das informações contábeis gerenciais no processo decisório destas empresas.

\section{Estudos correlatos: MPEs e as informações contábeis gerenciais}

Stroeher e Freitas (2008) apresentaram que pesquisas realizadas com MPE apontam que as informações contábeis são utilizadas apenas para 0 atendimento das exigências fiscais. Percebe-se que o objetivo da contabilidade de fornecer informações úteis ao processo decisório das organizações pode não ser alcançado na realidade das MPEs, principalmente pela utilização de prestação de serviços contábeis externos, ou seja, não há atuação direta dos profissionais contábeis na gestão destas empresas (MIRANDA; FREIRE; SATURNINO, 2009).

Cunha, Rocha e Leal (2008, p. 07) expõem que os principais serviços de contabilidade oferecidos pelos profissionais contábeis são "escrituração contábil, conciliação de contas, demonstrações financeiras, declarações fiscais, arquivo manual e magnético de documentos". Neste contexto, observa-se que não são oferecidos aos clientes informações contábeis gerenciais como, por exemplo, um sistema de informações integrado para o processo decisório.

Segundo Peleias (2011), a especialização em gestão das pequenas empresas é mínima, a tecnologia disponibilizada é básica para atender às necessidades operacionais e a estrutura organizacional possui características simples. O autor salienta que é importante auxiliar as MPEs a resolverem seus problemas de gestão, com a aplicação dos preceitos e ferramentas disponíveis oferecidas pela contabilidade gerencial, o que poderá contribuir com a continuidade das empresas.

As pesquisas sobre práticas gerenciais em pequenas empresas, abordam a relação com a gestão financeira e a avaliação de desempenho (THORNHILL; AMIT, 2003; SELS et al., 2006; MIZUMOTO et al., 2010; FENING; PESAKOVIC; AMARIA, 2008). Segundo Fening, Pesakovic e Amaria (2008) a adoção de práticas gerenciais apropriadas tem impacto positivo sobre o desempenho das pequenas empresas, o

BORGES, L. F. M.; LEAL, E. A. Utilidade da informação contábil gerencial na gestão das micro e pequenas empresas: um estudo com empresas do Programa Empreender de Uberlândia - MG. Revista de Empreendedorismo e Gestão de Pequenas Empresas, v.4, n.3, 2015. 
que poderá influenciar no aumento da probabilidade de continuidade das pequenas empresas no mercado (MIZUMOTO et al., 2010; THORNHILL; AMIT, 2003).

Com o intuito de investigar a gestão das MPEs, alguns estudos foram desenvolvidos com o objetivo de verificar como as informações contábeis gerenciais são utilizadas nestes empreendimentos. Faria, Azevedo e Oliveira (2012) verificaram a utilidade das informações contábeis na gestão de MPE do ramo de comércio de materiais de construção em uma cidade na Bahia. Como resultado, pôde-se observar que muitos dos gestores desconheciam as ferramentas contábeis gerenciais e acreditavam que a contabilidade estava voltada para o atendimento das exigências fiscais e trabalhistas. A maioria dos gestores possuía apenas o Ensino Médio e não tinham conhecimento sobre as informações contábeis para gestão do negócio e, por isso, priorizavam suas experiências para embasar as decisões acerca do negócio.

Quanto às práticas gerenciais, Vogel e Wood Junior (2012) investigaram como os empresários bem-sucedidos definiam tais práticas, identificando quais eram adotadas pelas MPEs. Os pesquisadores concluíram que os pequenos gestores atribuem importância à prática gerencial e reconhecem sua relevância para o sucesso do negócio, porém, por desconhecimento ou falta de recursos, ela não é aplicada.

Nesse mesmo contexto, Almeida et al. (2013) observaram que algumas empresas investem em recursos na parte operacional, contudo, não há uma integração para a concepção e utilização de informações gerenciais.

O estudo de Albuquerque et al. (2013) avaliou a utilização de indicadores e relatórios contábeis por MPE, bem como o padrão e intensidade do uso para empresas de Manaus (AM). Foi observado que as MPEs não utilizam com frequência os indicadores, relatórios e informações contábeis para embasar as decisões. Os relatórios indicados com maior uso pelos gestores das pequenas empresas foram "Demonstração do Resultado do Exercício", "Balanço Patrimonial”, "Livro e Fluxo de Caixa", e ainda os controles de contas a pagar e a receber.

Segundo os autores, tais resultados evidenciam que os gestores possuem foco em dados que suportem a tomada de decisão a curto prazo, o que revela uma

BORGES, L. F. M.; LEAL, E. A. Utilidade da informação contábil gerencial na gestão das micro e pequenas empresas: um estudo com empresas do Programa Empreender de Uberlândia - MG. Revista de Empreendedorismo e Gestão de Pequenas Empresas, v.4, n.3, 2015. 
falta de estratégia para médio e longo prazo. Essas projeções são importantes e poderiam assegurar uma sobrevivência no mercado.

Observou-se nos estudos apresentados, uma homogeneidade na baixa utilização das informações contábeis gerenciais. Os principais motivos são: o desconhecimento (qualificação do gestor) ou a falta de recursos para implementação de sistemas de informações. Além disso, os estudos evidenciaram que os gestores apontam que a função da contabilidade está voltada ao atendimento do fisco e legislação trabalhista.

No próximo tópico apresentam-se os conceitos e finalidades da contabilidade gerencial pesquisados na literatura.

\section{Contabilidade gerencial: conceitos e finalidades}

A Contabilidade se divide em duas vertentes: a contabilidade financeira e a gerencial. A principal diferença entre elas é o foco no usuário: a primeira busca atender as necessidades do usuário externo e a segunda, as necessidades do usuário interno (FREZATTI; AGUIAR; GUERREIRO, 2006).

Santos (2009) indica que a contabilidade financeira tem a finalidade de atender às exigências fiscais, pois é por meio dela que são realizadas as tributações e arrecadações de impostos. Horngren, Sundem e Stratton (2004, p.4) classificam a contabilidade gerencial como "processo de identificar, mensurar, acumular, analisar, preparar, interpretar e comunicar informações que auxiliem os gestores a atingir objetivos organizacionais".

Segundo Atkinson et al. (2000), a contabilidade gerencial é responsável pelas informações operacionais e financeiras destinadas aos usuários internos e tais informações devem ser direcionadas conforme a necessidade dos gestores.

Fernandes, Klann e Figueredo (2011) complementam que a contabilidade gerencial é voltada para a administração da organização, tendo como propósito, fornecer informações que sejam adequadas ao modelo decisório do gestor. Nesta perspectiva, ela é considerada como um instrumento fundamental para o processo de gestão do empreendimento.

BORGES, L. F. M.; LEAL, E. A. Utilidade da informação contábil gerencial na gestão das micro e pequenas empresas: um estudo com empresas do Programa Empreender de Uberlândia - MG. Revista de Empreendedorismo e Gestão de Pequenas Empresas, v.4, n.3, 2015. 
Quanto às principais diferenças apresentadas entre a contabilidade financeira e gerencial, Ching (2006) e Frezatti, Aguiar e Guerreiro (2006) não fazem uma abordagem focada somente nos usuários, mas incluem o tipo de informação, a tempestividade, natureza da informação, restrições, escopo e comportamento, dentre outros aspectos, conforme abordado no Quadro 2, a seguir.

Quadro 2 - Diferenças entre contabilidade financeira e gerencial

\begin{tabular}{|c|c|c|}
\hline & Contabilidade Financeira & Contabilidade Gerencial \\
\hline Usuários & $\begin{array}{l}\text { Primordialmente o público } \\
\text { externo; usuários } \\
\text { generalizados }\end{array}$ & $\begin{array}{l}\text { Pessoas dentro da organização; } \\
\text { usuários específicos }\end{array}$ \\
\hline $\begin{array}{l}\text { Tipo de } \\
\text { informação }\end{array}$ & Somente medidas financeiras & $\begin{array}{c}\text { Medidas financeiras mais } \\
\text { informações operacionais e físicas } \\
\text { (não financeiras) }\end{array}$ \\
\hline Foco do tempo & $\begin{array}{l}\text { Foco nas informações } \\
\text { passadas }\end{array}$ & $\begin{array}{l}\text { Informações que permitam entender, } \\
\text { planejar e prever o futuro }\end{array}$ \\
\hline $\begin{array}{l}\text { Natureza da } \\
\text { informação }\end{array}$ & $\begin{array}{l}\text { Objetividade dos dados, } \\
\text { confiável e auditável }\end{array}$ & $\begin{array}{c}\text { Énfase na relevância dos dados, } \\
\text { subjetiva e flexível }\end{array}$ \\
\hline Restrição & $\begin{array}{c}\text { Regras definidas por princípios } \\
\text { contábeis e autoridades } \\
\text { governamentais }\end{array}$ & $\begin{array}{c}\text { Sistemas e informações para } \\
\text { atender às necessidades dos } \\
\text { usuários }\end{array}$ \\
\hline Escopo & $\begin{array}{c}\text { Informações agregadas e } \\
\text { resumidas sobre a } \\
\text { organização como um todo }\end{array}$ & $\begin{array}{c}\text { Informações desagregadas, } \\
\text { relatórios sobre produtos, clientes e } \\
\text { em qualquer nível }\end{array}$ \\
\hline Comportamento & $\begin{array}{c}\text { Preocupação com o modo } \\
\text { como os números da empresa } \\
\text { irão afetar o comportamento } \\
\text { externo }\end{array}$ & $\begin{array}{c}\text { Preocupação com o modo como as } \\
\text { medidas e os relatórios irão } \\
\text { influenciar o comportamento dos } \\
\text { gerentes }\end{array}$ \\
\hline $\begin{array}{l}\text { Órgãos } \\
\text { reguladores ou } \\
\text { definidores de } \\
\text { regra }\end{array}$ & $\begin{array}{c}\text { Atendem as regras impostas } \\
\text { por órgãos para elaboração } \\
\text { dos relatórios }\end{array}$ & $\begin{array}{c}\text { As normas são utilizadas não por } \\
\text { imposição, mas sim por } \\
\text { conveniência }\end{array}$ \\
\hline $\begin{array}{l}\text { Profissional } \\
\text { especializado }\end{array}$ & $\begin{array}{c}\text { Em alguns países, apenas o } \\
\text { profissional contábil registrado } \\
\text { no conselho pode se } \\
\text { responsabilizar pelos relatórios } \\
\text { contábeis }\end{array}$ & $\begin{array}{l}\text { Não existe um profissional } \\
\text { específico que pode fazer }\end{array}$ \\
\hline
\end{tabular}

Fonte: Adaptado de Ching (2006); Frezatti, Aguiar e Guerreiro (2006).

Verifica-se que as diferenças abordadas pela contabilidade financeira e gerencial não abrangem especificamente o tipo de usuário de tais informações. É importante ressaltar a relevância do tipo de informação produzida e o foco no tempo. As informações contábeis gerenciais permitem realizar uma previsão para o futuro ao auxiliar no planejamento da empresa. A ausência de regras e normas impostas BORGES, L. F. M.; LEAL, E. A. Utilidade da informação contábil gerencial na gestão das micro e pequenas empresas: um estudo com empresas do Programa Empreender de Uberlândia - MG. Revista de Empreendedorismo e Gestão de Pequenas Empresas, v.4, n.3, 2015. 
para a contabilidade gerencial reflete em uma flexibilização para a organização dos relatórios gerenciais conforme a necessidade do usuário (FREZATTI; AGUIAR; GUERREIRO, 2006).

Nesse contexto, Atkinson et al. (2000, p. 36) abordam que "a informação gerencial contábil é uma das fontes informacionais primárias para a tomada de decisão e controle nas empresas". Essas informações auxiliam os gestores a tomarem decisões de natureza operacional e estratégica, auxiliando-os a alcançar os objetivos de curto e longo prazo das empresas (MEGLIORINI; RODRIGUES; PEREIRA, 2011).

Segundo Horngren, Sundem e Stratton (2004), as informações contábeis são utilizadas, em geral, por usuários em três categorias, conforme apresentado no Quadro 3, a seguir.

Quadro 3 - Usuários da informação contábil

\begin{tabular}{|l|c|}
\hline Usuários & Finalidade \\
\hline $\begin{array}{l}\text { Internos - Nível } \\
\text { gerencial }\end{array}$ & $\begin{array}{c}\text { Embasar o planejamento e controle a curto prazo, de } \\
\text { operações rotineiras. }\end{array}$ \\
\hline Internos- CEO & $\begin{array}{r}\text { Embasar processo decisório em operações não rotineiras, } \\
\text { formular políticas gerais e ainda planos de longo prazo. }\end{array}$ \\
\hline Externos & $\begin{array}{c}\text { Embasar decisões a respeito da empresa, como por exemplo, } \\
\text { aquisição de ações, quantidade de imposto recolhido. }\end{array}$ \\
\hline
\end{tabular}

Fonte: Adaptado de Horngren, Sundem e Stratton (2004, p. 4)

Para complementar, Atkinson et al. (2000, p. 45) indicam as funções das informações contábeis gerenciais, que abrangem:

(I) Controle Operacional: informações sobre a eficiência e qualidade das tarefas executadas; (II) Custeio do Produto e do Cliente: mensura os custos entre se produzir, vender e entregar o produto ou serviço aos clientes; (III) Controle Administrativo: fornece informação sobre o desempenho dos gerentes ou unidades operacionais; e, (IV) Controle Estratégico: fornece informações sobre o desempenho financeiro e competitivo de longo prazo, condições do mercado, preferências dos clientes e inovações tecnológicas.

BORGES, L. F. M.; LEAL, E. A. Utilidade da informação contábil gerencial na gestão das micro e pequenas empresas: um estudo com empresas do Programa Empreender de Uberlândia - MG. Revista de Empreendedorismo e Gestão de Pequenas Empresas, v.4, n.3, 2015. 
Observa-se a importância da aplicação das informações fornecidas pela contabilidade gerencial para auxiliar o processo decisório de uma organização, visando a avaliação de desempenho e continuidade de suas atividades no mercado em que está inserida.

Assim, Miranda, Freire e Saturnino (2009, p. 134) indicam o importante papel a ser exercido pelo contador, informando que ele tem a responsabilidade "de orientar o administrador a tomar decisões nas diversas áreas do empreendimento".

Megliorini, Rodrigues e Pereira (2011) destacam que nas MPEs, a prestação de serviços normalmente é terceirizada. Os profissionais oferecem basicamente os relatórios e informações impostos por lei. Os autores complementam que, independente da contabilidade da empresa ser interna, as informações contábeis devem ser geradas para atender aos usuários externos e também aos gestores internos no processo decisório (MEGLIORINI; RODRIGUES; PEREIRA, 2011).

No próximo tópico, apresentam-se os procedimentos metodológicos adotados neste estudo com o propósito de atingir o objetivo proposto.

\section{Classificação da pesquisa}

Com o intuito de atingir o objetivo do trabalho de investigar qual a importância atribuída pelos gestores das micro e pequenas empresas às informações contábeis gerenciais, bem como identificar a frequência de utilização dessas informações, utilizou-se de métodos mistos, que abrangem as abordagens qualitativa e quantitativa.

Tais abordagens foram associadas para tratamento dos dados a fim de explorar os resultados de forma mais eficiente. Para Creswell (2007, p. 33), "os pesquisadores tentam elaborar ou expandir os resultados de um método com outro método", caracterizando assim, os métodos mistos.

$\mathrm{Na}$ abordagem qualitativa, realizou-se entrevistas com os gestores, já na abordagem quantitativa, houve aplicação dos questionários, os dados foram tratados estatisticamente, com o intuito de relatar qual a importância atribuída pelos pequenos gestores às informações gerenciais.

BORGES, L. F. M.; LEAL, E. A. Utilidade da informação contábil gerencial na gestão das micro e pequenas empresas: um estudo com empresas do Programa Empreender de Uberlândia - MG. Revista de Empreendedorismo e Gestão de Pequenas Empresas, v.4, n.3, 2015. 
A pesquisa foi dividida em duas fases, na primeira desenvolveram-se as etapas da pesquisa qualitativa, e na segunda, as etapas quantitativas.

Inicialmente entrou-se em contato com o coordenador do Programa Empreender de Uberlândia - MG, que prontamente concedeu a listagem das empresas participantes do projeto. O programa é gerenciado pela Associação Comercial e Industrial de Uberlândia (ACIUB) em parceria com o Sebrae e Prefeitura Municipal de Uberlândia-MG, tendo como objetivo mobilizar os micro e pequenos empresários na troca de experiência, auxiliando-os na conquista de mercado e desenvolvimento da região.

No Programa Empreender, os gestores são divididos em núcleos setoriais, ou seja, eles são agrupados por setor de atuação. Ao total, o programa possui 11 núcleos setoriais. Após a exclusão de alguns núcleos (sacoleiras, contadores, escolas entre outros), devido a inviabilidade de participação por não terem estrutura física, ou contato restrito, entrou-se em contato e realizou-se o convite aos gestores para participarem da pesquisa.

Assim, na primeira fase da pesquisa, as entrevistas foram realizadas com a utilização de um roteiro semiestruturado para coleta de dados. Elas foram previamente agendadas com duração de quarenta minutos aproximadamente cada, sendo realizadas nas próprias empresas, no período de 06 a 17 de fevereiro de 2013.

O roteiro semiestruturado possuía, inicialmente questões para a caracterização dos respondentes, seguida de questões voltadas a alcançar o objetivo da pesquisa, a saber: ferramentas de controle gerencial, frequência de utilização e ainda questões sobre a finalidade que as informações contábeis possuem e utilidade que eles percebem da mesma.

Realizou-se as entrevistas com uma amostra de 9 gestores de MPEs vinculados ao Programa Empreender de Uberlândia-MG sendo estes oriundos aos núcleos "Transporte e Logística" "Material de Construção" e "Academias de Ginástica e Dança". Em cada um deles, três empresas participaram. A escolha destes núcleos foi por conveniência, devido à acessibilidade.

BORGES, L. F. M.; LEAL, E. A. Utilidade da informação contábil gerencial na gestão das micro e pequenas empresas: um estudo com empresas do Programa Empreender de Uberlândia - MG. Revista de Empreendedorismo e Gestão de Pequenas Empresas, v.4, n.3, 2015 
No momento da pesquisa, foi feito contato com as empresas conforme indicação do coordenador do Programa Empreender. Todos $s$ gestores foram convidados a participar da pesquisa e a reunião foi posteriormente agendada para a realização da entrevista. Ao total, 10 empresas aceitaram participar da pesquisa, porém, uma foi excluída visto que não se enquadrava nos critérios de MPE adotados neste trabalho.

Em relação aos procedimentos técnicos na segunda etapa, a coleta de dados ocorreu por meio do levantamento (survey). O instrumento (questionário) foi organizado baseado na literatura pesquisada para este estudo $O$ questionário estava estruturado em três partes. A primeira refere-se à caracterização do respondente. A segunda apresenta alternativas referentes à utilidade das informações contábeis gerenciais e frequência de utilização das ferramentas de controle gerencial. A última evidencia questões sobre finalidade e utilidades das informações gerenciais no processo decisório.

Para a segunda etapa do questionário, disponibilizou-se uma escala likert de cinco pontos. Em relação à utilidade das informações, a escala varia de 1 "nada importante" a 5 "muito importante". Já na parte da frequência de utilização, a escala varia de 1 "nunca é utilizada" a 5 "muito utilizada".

Para a aplicação dos questionários, foi solicitada a autorização do coordenador do Programa Empreender, que indicou os dias em que aconteceria as reuniões, assim, a coleta foi realizada nas reuniões dos núcleos setoriais agendadas pelo programa. Essas reuniões ocorreram no mês de Março/2014.

A população participante do estudo são as $120 \mathrm{MPEs}$, vinculadas ao Programa Empreender, referentes a 11 núcleos setoriais. A escolha da amostra foi aleatória devido à viabilidade da realização do estudo. A amostra do estudo foi composta por 75 gestores que dispuseram a responder 0 instrumento, correspondendo a $63 \%$ de todas as MPEs participantes dos núcleos selecionados para a pesquisa, conforme apresentado na Tabela 1.

BORGES, L. F. M.; LEAL, E. A. Utilidade da informação contábil gerencial na gestão das micro e pequenas empresas: um estudo com empresas do Programa Empreender de Uberlândia - MG. Revista de Empreendedorismo e Gestão de Pequenas Empresas, v.4, n.3, 2015. 
Tabela 1 - Participação por núcleo da amostra selecionada

\begin{tabular}{|c|c|c|c|}
\hline Núcleos participantes & $\begin{array}{c}\text { № de } \\
\text { empresas } \\
\text { associadas } \\
\end{array}$ & $\begin{array}{c}\text { № de } \\
\text { empresas } \\
\text { participantes } \\
\end{array}$ & $\begin{array}{c}\% \text { de } \\
\text { participação em } \\
\text { cada núcleo } \\
\end{array}$ \\
\hline Academias (NAUD) & 15 & 12 & $80 \%$ \\
\hline Agências de Turismo & 12 & 8 & $67 \%$ \\
\hline Bares e Casas Noturnas & 9 & 4 & $44 \%$ \\
\hline $\begin{array}{l}\text { Chaveiros Profissionais da } \\
\text { ACIUB }\end{array}$ & 11 & 11 & $100 \%$ \\
\hline Mercado Municipal & 11 & 7 & $64 \%$ \\
\hline Ópticas da ACIUB & 14 & 8 & $57 \%$ \\
\hline Rede Casa & 5 & 4 & $80 \%$ \\
\hline Rede Cerrado & 10 & 3 & $30 \%$ \\
\hline $\begin{array}{l}\text { Transporte Logística Integrada } \\
\text { (NTLI) }\end{array}$ & 11 & 6 & $55 \%$ \\
\hline UdiFoods & 15 & 6 & $40 \%$ \\
\hline Univídeo & 7 & 6 & $86 \%$ \\
\hline TOTAL & 120 & 75 & $63 \%$ \\
\hline
\end{tabular}

Fonte: Os autores (2015).

Importante ressaltar que a amostra é composta por representantes de 11 núcleos pertencentes ao Programa Empreender e a menor participação foi a da Rede Cerrado (grupo de pequenos supermercados).

\section{Análise dos dados}

$\mathrm{Na}$ primeira fase da pesquisa, realizou-se a análise de conteúdo das entrevistas coletadas de forma objetiva e sistemática, com o objetivo de compreender e identificar o que foi dito a respeito do tema em estudo (BARDIN, 2002; MARTINS; THEÓPHILO, 2007).

O roteiro da entrevista apresentava três categorias para análise, a primeira, utilidade das ferramentas contábeis tinha o objetivo de identificar os principais artefatos contábeis utilizados nas empresas. A segunda, buscava identificar a frequência de utilização, e a última, questões relacionadas a finalidade e utilidade atribuída pelos gestores as informações contábeis.

$\mathrm{Na}$ segunda fase, utilizou-se a análise descritiva e também o teste de comparações múltiplas de proporções proposto por Biase e Ferreira (2009). O teste

BORGES, L. F. M.; LEAL, E. A. Utilidade da informação contábil gerencial na gestão das micro e pequenas empresas: um estudo com empresas do Programa Empreender de Uberlândia - MG. Revista de Empreendedorismo e Gestão de Pequenas Empresas, v.4, n.3, 2015. 
estatístico foi utilizado com o intuito de comparar as proporções de importância atribuída às informações contábeis gerencias na gestão do empreendimento e também a proporção de frequência de utilização das ferramentas de controle gerencial.

Para o referido teste, a hipótese nula é a de que não existe diferença entre as proporções avaliadas, sendo que o teste foi processado considerando um nível de significância de 5\% para análise das hipóteses.

A estatística proposta por Biase e Ferreira (2009) para o teste está apresentada na Equação 1.

$$
\mathrm{x}^{2}=\frac{\left(\hat{\pi}_{i}, \hat{\pi}_{i^{\prime}}\right)^{2}}{\operatorname{var}\left(\hat{\pi}_{i}\right)+\operatorname{var}\left(\hat{\pi}_{i^{\prime}}\right)-2 \operatorname{cov}\left(\hat{\pi}_{i}, \hat{\pi}_{i^{\prime}}\right)} \quad \text { Equação (1) }
$$

Após realização das entrevistas, procedeu-se com a transcrição das mesmas e categorização das respostas, visto que as entrevistas foram norteadas por um roteiro semiestruturado, conforme descrito nos procedimentos metodológicos. As falas dos entrevistados favorecia a categorização. Cabe destacar que os relatos pessoais ou que fugiam do objetivo central do trabalho foram descartados.

Para a caracterização das nove empresas pesquisadas, verificou-se que quatro delas já atuavam no mercado há mais de dez anos. Na maioria das empresas, a contabilidade era terceirizada e havia vínculos familiares entre os funcionários (duas características comuns das MPEs).

Quanto à qualificação dos gestores entrevistados, sete deles indicaram que possuíam ou estavam cursando algum curso superior (nenhum na área de negócios). Tais resultados foram divergentes dos resultados do estudo de Faria, Azevedo e Oliveira (2012), que constataram que a maioria dos pequenos gestores possuía apenas o Ensino Médio, comprovando que os gestores das MPE normalmente não possuem formaçao na área de negócios

Quando questionados quanto ao uso e importância das ferramentas de controle gerencial, os gestores citaram alguns controles que utilizavam como, por exemplo: gestão de custos, fluxo de caixa projetado, análise da margem de lucro,

BORGES, L. F. M.; LEAL, E. A. Utilidade da informação contábil gerencial na gestão das micro e pequenas empresas: um estudo com empresas do Programa Empreender de Uberlândia - MG. Revista de Empreendedorismo e Gestão de Pequenas Empresas, v.4, n.3, 2015. 
entre outros. Quanto à utilização e frequência de uso das informações gerenciais, todos os gestores entrevistados consideram as ferramentas como muito importante e informaram que utilizam o fluxo de caixa, complementado por controle de contas a pagar e a receber para o processo decisório.

Vogel e Wood Junior (2012) também evidenciaram a importância das ferramentas de controle gerencial na percepção dos gestores de pequenas empresas. Em relação às ferramentas apontadas com maior frequência de uso, os resultados encontrados são convergentes com os achados de Albuquerque et al. (2013), que identificaram também o fluxo de caixa, controles de contas a pagar e a receber.

Os gestores entrevistados indicaram que a análise de informações não financeiras como, por exemplo, fatores econômicos e atuação da concorrência, são fundamentais para o sucesso do negócio. Tais informações, normalmente, são discutidas nas reuniões quinzenais realizadas com os núcleos da mesma área de atuação propostas pelo Programa Empreender.

Em relação à finalidade e utilidade da informação contábil gerencial, os gestores a utilizam para avaliar os impactos financeiros, isto é, para saber sobre o desempenho do negócio e acompanhar as metas propostas. Segundo Thornhill e Amit (2003), as fragilidades na gestão financeira é uma das principais causas de mortalidades das pequenas empresas.

Verificou-se que apesar dos gestores considerarem muito importante as informações contábeis gerenciais, a maioria dos empresários afirmaram que algumas ferramentas não são implementadas por falta de conhecimento. Estes resultados são convergentes com o estudo de Vogel e Wood Junior (2012), em que muitos dos gestores indicaram não utilizar tais ferramentas pela falta de conhecimento ou recursos para implementá-las.

Quanto à frequência formal para análise dos relatórios gerenciais, não foi possível identificar a periodicidade de suas utilizações, assim como o estudo de Albuquerque et al. (2013) verificou que não há uma frequência de utilização de relatórios gerenciais para embasar as decisões dos gestores de MPEs. O Quadro 4 apresenta um resumo dos resultados coletados nas entrevistas, referentes à

BORGES, L. F. M.; LEAL, E. A. Utilidade da informação contábil gerencial na gestão das micro e pequenas empresas: um estudo com empresas do Programa Empreender de Uberlândia - MG. Revista de Empreendedorismo e Gestão de Pequenas Empresas, v.4, n.3, 2015. 
percepção dos gestores entrevistados nas pequenas empresas quanto às ferramentas de controle gerencial, a frequência do uso dos relatórios gerenciais e a finalidade e utilidade da informação contábil gerencial.

Quadro 4 - Resumo dos resultados da análise qualitativa

\begin{tabular}{|c|c|}
\hline Descrição & Resultados Encontrados \\
\hline $\begin{array}{c}\text { Ferramentas de Controle } \\
\text { Gerencial }\end{array}$ & $\begin{array}{l}\text { - } \quad \text { Consideram como "Muito Importante"; } \\
\text { - } \quad \text { Mais utilizada: Fluxo de Caixa, complementada com } \\
\text { controle de contas a receber, a pagar e controle de } \\
\text { vendas } \\
\text { - } \quad \text { Falta de conhecimento é o principal fator de não } \\
\text { utilização; } \\
\text { - "[...] não adianta um relatório montado e lançado, sem } \\
\text { que o gestor saiba analisar, pois é necessária a } \\
\text { existência dessa análise. Muitas vezes, nós, gestores, } \\
\text { encontramos dificuldades para realizar essa análise." } \\
\text { (informação verbal - gestora 3); } \\
\text { - Informações não financeiras: troca de informações } \\
\text { propiciadas pelo Programa Empreender } \\
\text { - Formação do Preço de Venda: análise dos } \\
\text { concorrentes } \\
\text { - Orçamento financeiro: apesar de atribuírem } \\
\text { importância, apenas dois gestores utilizam; } \\
\text { "Após adesão ao Programa Empreender, passei a dar } \\
\text { mais importância para esta parte do orçamento, e por } \\
\text { falta de conhecimento em como executar, contratei } \\
\text { uma funcionária qualificada para auxiliar no negócio. Jáa } \\
\text { percebi um aumento nos resultados de } \\
\text { aproximadamente quatro vezes a mais após o } \\
\text { planejamento proposto no orçamento." (informação } \\
\text { verbal - gestor 9). }\end{array}$ \\
\hline Frequência/periodicidade & $\begin{array}{l}\text { - Fluxo de caixa analisado diariamente; } \\
\text { - Todas as outras ferramentas apresentadas foram } \\
\text { apontadas com frequência indeterminada, sendo } \\
\text { utilizadas de acordo com a necessidade de decisão. }\end{array}$ \\
\hline $\begin{array}{l}\text { Finalidade e Utilidade da } \\
\text { Informação Contábil } \\
\text { Gerencial }\end{array}$ & $\begin{array}{l}\text { - Três gestores apontaram que suas decisões são } \\
\text { embasadas na experiência dos mesmos no negócio; } \\
\text { outros três principalmente na sensibilidade e } \\
\text { experiência do gestor; } \\
\text { - As informações contábeis gerenciais são utilizadas } \\
\text { principalmente para acompanhar metas e avaliar os } \\
\text { impactos financeiros no negócio; } \\
\text { "[...] a informação gerencial é importante demais para o } \\
\text { pequeno empresário, porque ele vê a rentabilidade do } \\
\text { negócio, vê a perspectiva de crescimentos, se tem } \\
\text { recursos para investimento, se está no caminho certo, } \\
\text { se o negócio é viável." (informação verbal - gestor 2). }\end{array}$ \\
\hline
\end{tabular}

Fonte: Os autores (2015)

BORGES, L. F. M.; LEAL, E. A. Utilidade da informação contábil gerencial na gestão das micro e pequenas empresas: um estudo com empresas do Programa Empreender de Uberlândia - MG. Revista de Empreendedorismo e Gestão de Pequenas Empresas, v.4, n.3, 2015. 
Para complementar os resultados e alcançar um maior quantidade de gestores de pequenas empresas, apresenta-se a análise dos resultados identificados com a aplicação do questionário, ou seja, a análise quantitativa dos dados coletados. Dessa forma, fazem parte da amostra, nesta fase da pesquisa, 75 participantes (gestores de pequenas empresas).

A Tabela 2 evidencia a caracterização dos respondentes participantes do estudo e dados da empresa.

Tabela 2 - Caracterização dos Respondentes

\begin{tabular}{|c|c|c|c|}
\hline \multicolumn{2}{|l|}{ Sexo } & \multicolumn{2}{|c|}{ Idade } \\
\hline $78,7 \%$ Feminino & $21,3 \%$ & Até 20 anos & $6,7 \%$ \\
\hline \multicolumn{2}{|l|}{ Cargo do respondente } & De 21 a 30 anos & $16 \%$ \\
\hline Proprietário & $52 \%$ & De 31 a 40 anos & $22,7 \%$ \\
\hline Sócio-gerente & $29,3 \%$ & De 41 a 50 anos & $36 \%$ \\
\hline Gerente da empresa & $17,3 \%$ & 50 anos acima & $18,7 \%$ \\
\hline Não informado & $1,3 \%$ & Não informado & $0 \%$ \\
\hline \multicolumn{4}{|c|}{ Nível de escolaridade } \\
\hline Até a 4⿳亠丷a série primária & $5.3 \%$ & $\begin{array}{l}\text { Cursando o ensino } \\
\text { superior }\end{array}$ & $17.3 \%$ \\
\hline Até a $8^{\mathrm{a}}$ série do $1^{\circ} \mathrm{grau}$ & $13,3 \%$ & Superior & $12 \%$ \\
\hline Até o $3^{\circ}$ ano do ensino médio & $33,3 \%$ & Pós-graduação & $4 \%$ \\
\hline Nível técnico & $14,7 \%$ & Outros & $0 \%$ \\
\hline \multicolumn{4}{|c|}{ Tempo de funcionamento da empresa } \\
\hline Até 01 ano & $2,7 \%$ & De 02 a 05 anos & $24 \%$ \\
\hline De 01 a 02 anos & $12 \%$ & Acima de 05 anos & $61,3 \%$ \\
\hline \multicolumn{4}{|c|}{ Número de funcionários } \\
\hline De 0 a 05 & $46,7 \%$ & De 16 a 20 & $9,3 \%$ \\
\hline De 06 a 10 & $22,7 \%$ & Acima de 20 & $8 \%$ \\
\hline De 11 a 15 & $13,3 \%$ & Outros & $0 \%$ \\
\hline Tempo de experiência no ramo d & tuação & \multicolumn{2}{|c|}{$\begin{array}{l}\text { Os funcionários possuem laços } \\
\text { familiares }\end{array}$} \\
\hline Menos de 01 ano & $4 \%$ & Sim/totalidade & $33,3 \%$ \\
\hline De 01 a 05 anos & $25,3 \%$ & Não & $41,3 \%$ \\
\hline Mais de 05 anos & $70,7 \%$ & Parcialmente & $25,3 \%$ \\
\hline \multicolumn{4}{|c|}{ A contabilidade da empresa é feita } \\
\hline Interna - própria empresa & $18,9 \%$ & Externa - por terceiros & $81,1 \%$ \\
\hline
\end{tabular}

Fonte: Os autores (2015)

Observou-se que a maioria dos participantes são proprietários do empreendimento (52\%) e o maior percentual referente à qualificação é o Ensino Médio completo (33,3\%). Quanto ao tempo de experiência no ramo de atuação,

BORGES, L. F. M.; LEAL, E. A. Utilidade da informação contábil gerencial na gestão das micro e pequenas empresas: um estudo com empresas do Programa Empreender de Uberlândia - MG. Revista de Empreendedorismo e Gestão de Pequenas Empresas, v.4, n.3, 2015 . 
grande parte da amostra (70,7\%) possui mais de cinco anos - resultados convergentes com o estudo de Faria, Azevedo e Oliveira (2012).

Em relação à utilização de serviços contábeis, interno ou externo, o maior percentual (81\%) utiliza os serviços terceirizados (externos), o que foi evidenciado também por Megliorini, Rodrigues e Pereira (2011). Referente ao tempo de funcionamento, as pequenas empresas investigadas estão há mais de cinco anos no mercado (61,3\%). Tal característica é contrária ao perfil comum indicado para as MPEs, que é encerrar suas atividades nos primeiros cinco anos.

Quanto à caracterização dos respondentes, constatou-se que a maior parte da amostra está na faixa de idade de 31 a 50 anos (16\% e 22,7\%) e o sexo predominante dos gestores é masculino.

A Tabela 3 apresenta a importância atribuída pelos gestores de MPEs em relação à utilidade das informações gerenciais para a gestão da empresa.

Tabela 3 - Utilidade das Informações Gerenciais para a gestão da empresa

\begin{tabular}{|c|c|c|c|c|c|c|}
\hline Informações Gerenciais & 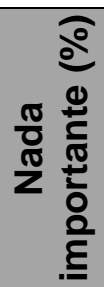 & 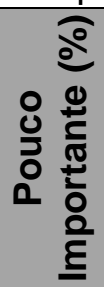 & 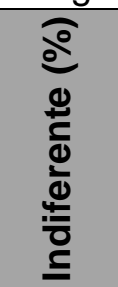 & 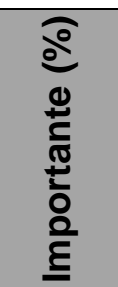 & 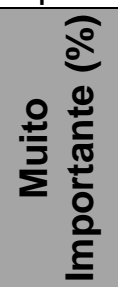 & $\frac{\widehat{ఠ}}{\frac{\pi}{0}}$ \\
\hline 1. Custos de produtos e/ou serviços & 1,33 & 0,00 & 5,33 & 18,67 & 74,67 & 100,00 \\
\hline 2. Orçamento operacional e financeiro & 0,00 & 1,33 & 9,33 & 17,33 & 72,00 & 100,00 \\
\hline 3. Fluxo de caixa & 0,00 & 0,00 & 4,00 & 21,33 & 74,67 & 100,00 \\
\hline 4. Nível de faturamento & 1,33 & 0,00 & 2,67 & 18,67 & 77,33 & 100,00 \\
\hline 5. Ponto de equilíbrio & 1,33 & 0,00 & 13,33 & 34,67 & 50,67 & 100,00 \\
\hline 6. Margem de lucro & 0,00 & 1,33 & 5,33 & 22,67 & 70,67 & 100,00 \\
\hline 7. Formação do preço de venda & 1,33 & 1,33 & 1,33 & 21,33 & 74,67 & 100,00 \\
\hline 8. Gestão de estoques & 1,33 & 1,33 & 4,00 & 36,00 & 57,33 & 100,00 \\
\hline 9. Controle das despesas & 0,00 & 0,00 & 6,67 & 12,00 & 81,33 & 100,00 \\
\hline 10. Endividamento & 4,00 & 2,67 & 10,67 & 10,67 & 72,00 & 100,00 \\
\hline 11. Planejamento tributário & 1,33 & 2,67 & 10,67 & 29,33 & 56,00 & 100,00 \\
\hline 12. Informações não financeiras & 2,67 & 5,33 & 16,00 & 46,67 & 29,33 & 100,00 \\
\hline
\end{tabular}

Fonte: Os autores (2015)

Observou-se que a maioria das informações gerenciais (como, por exemplo: custos dos produtos/serviços, nível de faturamento, controle de despesas, entre BORGES, L. F. M.; LEAL, E. A. Utilidade da informação contábil gerencial na gestão das micro e pequenas empresas: um estudo com empresas do Programa Empreender de Uberlândia - MG. Revista de Empreendedorismo e Gestão de Pequenas Empresas, v.4, n.3, 2015. 
outras) foram julgadas como "muito importante" por mais de $50 \%$ dos respondentes, exceto as Informações Não Financeiras, que obteve um percentual de $29,33 \%$ dos respondentes, mas complementou como "importante" por 46,6\%.

Verificou-se que as informações gerenciais sobre o endividamento tiveram a maior participação $(4,0 \%)$ na opção "nada importante". Apesar de ser um percentual pequeno, é importante ressaltá-lo, visto a relevância de tais informações para embasar decisões de financiamentos.

É importante destacar a convergência com os resultados nos estudos realizados por Vogel e Wood Junior (2012) e Albuquerque et al. (2013), sendo que em ambos, os achados apontam que os gestores consideram de suma importância as informações contábeis gerenciais para auxílio no negócio, porém, não conseguiram apontar a frequência de utilização.

Assim, com o propósito de identificar a frequência de uso das informações gerenciais, foram apresentadas algumas ferramentas de controle gerencial aos respondentes. Eles fizeram essa avaliação por meio de uma escala variando de "nunca utilizada" a "muito utilizada", contando ainda com a alternativa de "não conheço tal ferramenta", conforme apresentado na Tabela 4.

BORGES, L. F. M.; LEAL, E. A. Utilidade da informação contábil gerencial na gestão das micro e pequenas empresas: um estudo com empresas do Programa Empreender de Uberlândia - MG. Revista de Empreendedorismo e Gestão de Pequenas Empresas, v.4, n.3, 2015. 
Tabela 4 - Frequência de utilização das ferramentas de controle gerencial

\begin{tabular}{|c|c|c|c|c|c|c|}
\hline Frequência de utilização & 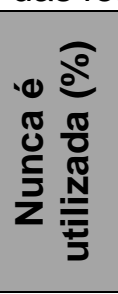 & 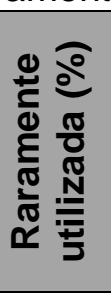 & 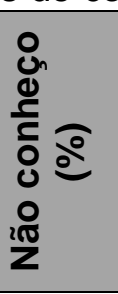 & 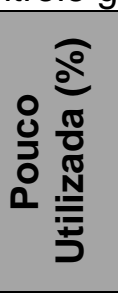 & 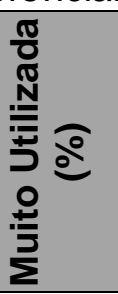 & 可 。 \\
\hline 1.Controle de contas a receber & 5,33 & 4,00 & 4,00 & 17,33 & 69,33 & 100,00 \\
\hline 2.Orçamento financeiro & 2,67 & 6,67 & 1,33 & 25,33 & 64,00 & 100,00 \\
\hline 3.Gestão de ativo permanente & 4,00 & 8,00 & 21,33 & 29,33 & 37,33 & 100,00 \\
\hline 4.Controle de custos & 4,00 & 2,67 & 4,00 & 13,33 & 76,00 & 100,00 \\
\hline 5.Controle orçamentário & 4,00 & 1,33 & 5,33 & 12,00 & 77,33 & 100,00 \\
\hline 6. Controle de fluxo de caixa & 4,00 & 1,33 & 4,00 & 8,00 & 82,67 & 100,00 \\
\hline 7.Orçamento de investimento & 6,67 & 2,67 & 6,67 & 32,00 & 52,00 & 100,00 \\
\hline 8.Controle de vendas & 1,33 & 0,00 & 2,67 & 10,67 & 85,33 & 100,00 \\
\hline 9.Controle de contas a pagar & 1,33 & 2,67 & 2,67 & 12,00 & 81,33 & 100,00 \\
\hline 10.Controle de investimento & 10,67 & 0,00 & 2,67 & 38,67 & 48,00 & 100,00 \\
\hline 11.Controle de estoques & 1,33 & 5,33 & 1,33 & 9,33 & 82,67 & 100,00 \\
\hline 12.Controle de despesas & 4,00 & 2,67 & 1,33 & 10,67 & 81,33 & 100,00 \\
\hline $\begin{array}{l}\text { 13.Controle de avaliação de resultado } \\
\text { (lucro) }\end{array}$ & 2,67 & 5,33 & 4,00 & 17,33 & 70,67 & 100,00 \\
\hline $\begin{array}{l}\text { 14.Controle de sistema de informação } \\
\text { gerencial }\end{array}$ & 5,33 & 8,00 & 8,00 & 36,00 & 42,67 & 100,00 \\
\hline 15.Orçamento operacional & 8,00 & 6,67 & 6,67 & 36,00 & 42,67 & 100,00 \\
\hline
\end{tabular}

Fonte: Os autores (2015)

Observou-se que grande parte das informações apresentadas, segundo os respondentes, são utilizadas com muita frequência, apresentando um percentual de respondentes acima de 60\%, exceto para as informações acerca da Gestão de Ativo Permanente, Orçamento e Controle de Investimento, Controle de Sistema de Informações Gerenciais e do Orçamento Operacional.

Destaca-se que as ferramentas de controle gerencial Orçamento e Controle de Investimento, Controle de Sistema de Informações e Orçamento Operacional apresentaram um percentual acima de 30\% de respondentes considerando-as pouco importante. Ou seja, tais informações que podem auxiliar no planejamento/controle das decisões de curto, médio e longo prazo, bem como as informações para o planejamento/gestão operacional são pouco utilizadas.

BORGES, L. F. M.; LEAL, E. A. Utilidade da informação contábil gerencial na gestão das micro e pequenas empresas: um estudo com empresas do Programa Empreender de Uberlândia - MG. Revista de Empreendedorismo e Gestão de Pequenas Empresas, v.4, n.3, 2015. 
Tais resultados vão de encontro com os resultados de Albuquerque et al. (2013), que verificaram que os gestores possuem foco em dados que suportem a tomada de decisão a curto prazo, demonstrando uma falta de estratégia para médio e longo prazo. Essas projeções são relevantes e poderiam assegurar uma sobrevivência no mercado.

Dentre as ferramentas destacadas, notou-se que quase $22 \%$ dos respondentes não conhecem a Gestão de Ativo Permanente, ou seja, não se faz nenhum controle sobre o imobilizado.

Após a análise descritiva, realizou-se um tratamento estatístico por meio da utilização do teste de comparação múltipla de proporção. Os resultados são apresentados na sequência.

Para analisar a importância atribuída pelos gestores às informações contábeis gerenciais, utilizou-se o teste de comparações múltiplas de proporção, considerando um nível de significância de $5 \%(0,05)$ para o teste. Neste sentido, foram testadas as seguintes hipóteses:

\section{$H_{0}$ : não existe diferença entre as proporções avaliadas.}

$H_{1}$ : existe diferença entre as proporções avaliadas.

Se o $p$-value das comparações de proporções forem menores ou iguais ao nível de significância empregada no teste (5\%), a hipótese nula será rejeitada. Se for o contrário, a hipótese não será rejeitada.

$\mathrm{Na}$ Tabela 5 são demonstrados os resultados obtidos pela avaliação da utilidade das informações contábeis gerencias na gestão do empreendimento. É importante ressaltar que a escala proposta aos respondentes varia de 1 a 5 , sendo 1 para "nada importante", 3 "indiferente" e 5 "muito importante".

BORGES, L. F. M.; LEAL, E. A. Utilidade da informação contábil gerencial na gestão das micro e pequenas empresas: um estudo com empresas do Programa Empreender de Uberlândia - MG. Revista de Empreendedorismo e Gestão de Pequenas Empresas, v.4, n.3, 2015. 
Tabela 5 - Teste de comparação múltipla entre as proporções atribuídas à utilidade das informações contábeis gerenciais

\begin{tabular}{|c|c|c|c|c|c|c|c|c|c|c|}
\hline $\begin{array}{l}\text { Utilidade das informações } \\
\text { gerenciais }\end{array}$ & $1 \times 2$ & $1 \times 3$ & $1 \times 4$ & $1 \times 5$ & $2 \times 3$ & $2 \times 4$ & $2 \times 5$ & $3 \times 4$ & $3 \times 5$ & $4 \times 5$ \\
\hline $\begin{array}{l}\text { 1. Custos de produtos e/ou } \\
\text { serviços }\end{array}$ & 0,997 & 0,984 & 0,133 & 0,000 & 0,955 & 0,086 & 0,000 & 0,383 & 0,000 & 0,000 \\
\hline $\begin{array}{l}\text { 2. Orçamento operacional e } \\
\text { financeiro }\end{array}$ & 0,997 & 0,728 & 0,133 & 0,000 & 0,866 & 0,199 & 0,000 & 0,827 & 0,000 & 0,000 \\
\hline 3. Fluxo de Caixa & 1,000 & 0,984 & 0,031 & 0,000 & 0,984 & 0,031 & 0,000 & 0,213 & 0,000 & 0,000 \\
\hline 4. Nível de faturamento & 0,999 & 0,999 & 0,133 & 0,000 & 0,996 & 0,086 & 0,000 & 0,199 & 0,000 & 0,000 \\
\hline 5. Ponto de Equilíbrio & 0,999 & 0,497 & 0,000 & 0,000 & 0,383 & 0,000 & 0,000 & 0,031 & 0,000 & 0,199 \\
\hline 6. Margem de Lucro & 0,999 & 0,955 & 0,017 & 0,000 & 0,984 & 0,031 & 0,000 & 0,134 & 0,000 & 0,000 \\
\hline 7. Formação do preço de venda & 1,000 & 1,000 & 0,052 & 0,000 & 1,000 & 0,052 & 0,000 & 0,052 & 0,000 & 0,000 \\
\hline 8. Gestão de estoques & 1,000 & 0,996 & 0,000 & 0,000 & 0,996 & 0,000 & 0,000 & 0,000 & 0,000 & 0,031 \\
\hline 9. Controle das Despesas & 1,000 & 0,903 & 0,497 & 0,000 & 0,903 & 0,497 & 0,000 & 0,955 & 0,000 & 0,000 \\
\hline 10. Endividamento & 0,999 & 0,903 & 0,903 & 0,000 & 0,826 & 0,826 & 0,000 & 1,000 & 0,000 & 0,000 \\
\hline 11. Planejamento Tributário & 0,999 & 0,728 & 0,001 & 0,000 & 0,826 & 0,002 & 0,000 & 0,085 & 0,000 & 0,002 \\
\hline $\begin{array}{l}\text { 12. Informações Não } \\
\text { Financeiras }\end{array}$ & 0,996 & 0,383 & 0,000 & 0,002 & 0,615 & 0,000 & 0,009 & 0,000 & 0,383 & 0,133 \\
\hline
\end{tabular}

Nota os valores em destaque na Tabela, representam aqueles que foram significantes ao nível nominal de $5 \%$

Fonte: Os autores (2015)

BORGES, L. F. M.; LEAL, E. A. Utilidade da informação contábil gerencial na gestão das micro e pequenas empresas: um estudo com

empresas do Programa Empreender de Uberlândia - MG. Revista de Empreendedorismo e Gestão de Pequenas Empresas, v.4, n.3, 2015. 
Os resultados apontam que, ao se comparar as proporções "nada importante" (1) com "pouco importante" (2) e "indiferente" (3), percebe-se que a hipótese nula foi aceita, pois não houve diferenças estatisticamente significantes entre as proporções ( $p$-value $>0,05$ ).

Quando comparadas as proporções de "nada importante" (1), "pouco importante" (2) ou "indiferente" (3) com "muito importante" (5), a hipótese nula foi rejeitada, demonstrando que há diferença significativa entre as proporções atribuídas de importância das informações contábeis gerenciais ( $p$-value $<0,05$ ).

Cabe ressaltar que ao se verificar a utilidade das informações não financeiras na gestão do negócio, houve aceitação da hipótese alternativa no cruzamento de "indiferente" e "muito importante", ou seja, há diferença na percepção dos gestores. O mesmo ocorreu com o cruzamento das proporções de "importante" (4) e "muito importante" (5) para as informações acerca do ponto de equilíbrio e as informações não financeiras. Os resultados corroboram os achados na análise descritiva, comprovando que os gestores consideram as informações contábeis gerenciais relevantes no processo decisório.

Para analisar a proporção da frequência/periodicidade de utilização das ferramentas de controle gerencial, os gestores avaliaram em uma escala de 1 a 5 , sendo 1 para "nunca utilizada", 3 para "não conheciam a ferramenta" e 5 para "muito utilizada". Os resultados são apresentados na Tabela 6.

BORGES, L. F. M.; LEAL, E. A. Utilidade da informação contábil gerencial na gestão das micro e pequenas empresas: um estudo com empresas do Programa Empreender de Uberlândia - MG. Revista de Empreendedorismo e Gestão de Pequenas Empresas, v.4, n.3, 2015. 
Tabela 6 - Teste de comparação múltipla entre as proporções atribuídas à frequência de utilização das ferramentas de controle gerencial

\begin{tabular}{|c|c|c|c|c|c|c|c|c|c|c|}
\hline Frequência de utilização & $1 \times 2$ & $1 \times 3$ & $1 \times 4$ & $1 \times 5$ & $2 \times 3$ & $2 \times 4$ & $2 \times 5$ & $3 \times 4$ & $3 \times 5$ & $4 \times 5$ \\
\hline 1.Controle de contas a receber & 0,999 & 0,999 & 0,497 & 0,000 & 1,000 & 0,383 & 0,000 & 0,383 & 0,000 & 0,000 \\
\hline 2.Orçamento financeiro & 984 & 0,999 & 0,017 & 0,000 & 0,955 & 0,085 & 0,000 & 0,009 & 0,000 & 0,000 \\
\hline 3.Gestão de Ativo Perma & 0,984 & 0,134 & 0,005 & 0,000 & 0,383 & 0,031 & 0,000 & 0,827 & 0,199 & 0,827 \\
\hline 4.Controle de Custos & 0,999 & 1,000 & 0,728 & 0,000 & 0,999 & 0,615 & 0,000 & 0,728 & 0,000 & 0,000 \\
\hline 5.Controle orçamentário & 0,996 & 0,999 & 0,826 & 0,000 & 0,984 & 0,615 & 0,000 & 0,903 & 0,000 & 0,000 \\
\hline 6.Controle de fluxo de ca & 0,996 & 1,000 & 0,984 & 0,000 & 0,996 & 0,903 & 0,000 & 0,984 & 0,000 & 0,000 \\
\hline 7.Orçamento de investimento & 0,984 & 1,000 & 0,005 & 0,000 & 0,984 & 0,000 & 0,000 & 0,005 & 0,000 & 0,052 \\
\hline 8.Controle & 0,999 & 0,999 & 0,728 & 0,000 & 0,996 & 0,615 & 0,000 & 0,823 & 0,000 & 0,000 \\
\hline 9.Controle de contas a & 0,999 & 0,999 & 0,615 & 0,000 & 1,000 & 0,728 & 0,000 & 0,728 & 0,000 & 0,000 \\
\hline 10.Controle de Investimento & 0,615 & 0,826 & 0,001 & 0,000 & 0,996 & 0,000 & 0,000 & 0,000 & 0,000 & 0,728 \\
\hline 11.Controle de estoques & 0,984 & 1,000 & 0,826 & 0,000 & 0,984 & 0,984 & 0,000 & 0,826 & 0,000 & 0,000 \\
\hline 12.Controle de despesas & 0,999 & 0,996 & 0,903 & 0,000 & 0,999 & 0,826 & 0,000 & 0,728 & 0,000 & 0,000 \\
\hline $\begin{array}{l}\text { 13.Controle de Avaliação de Resultado } \\
\text { (lucro) }\end{array}$ & 0,996 & 0,999 & 0,283 & 0,000 & 0,999 & 0,497 & 0,000 & 0,383 & 0,000 & 0,000 \\
\hline $\begin{array}{l}\text { 14.Controle de Sistema de Informação } \\
\text { Gerencial }\end{array}$ & 996 & 0,996 & 0,000 & 0,000 & 1,000 & 0,001 & 0,000 & 0,001 & ,000 & 0,903 \\
\hline 15.Orçamento Operacional & 99 & 999 & 001 & 0 & 1,000 & 0 & 0 & 0 & 0 & ),903 \\
\hline
\end{tabular}

Nota os valores em destaque na Tabela, representam aqueles que foram significantes ao nível nominal de $5 \%$ Fonte: Os autores (2015)

BORGES, L. F. M.; LEAL, E. A. Utilidade da informação contábil gerencial na gestão das micro e pequenas empresas: um estudo com empresas do Programa Empreender de Uberlândia - MG. Revista de Empreendedorismo e Gestão de Pequenas Empresas, v.4, n.3, 2015. 
Os resultados do teste evidenciam que, ao se comparar as proporções "nunca utilizada" (1) ou "pouco utilizada" (2) com "muito utilizada" (5), percebe-se que a hipótese nula foi rejeitada, ou seja, não houve diferenças significativas entre as proporções, o que mostra que as ferramentas de controle gerencial são muito utilizadas ( $p$-value $<0,05)$.

Para a proporção entre "não conheço" (3) ou "pouco utilizada" (4) com a frequência de "muito utilizada" (5), a hipótese nula não foi rejeitada apenas para a ferramenta de controle sobre gestão de ativo permanente, corroborando os achados da análise descritiva.

\section{Considerações finais}

O objetivo proposto para o presente estudo foi verificar a importância atribuída pelos gestores de micro e pequenas empresas às informações contábeis gerenciais, assim como a frequência de utilização das ferramentas de controle gerencial para gestão do negócio de MPEs vinculadas ao Programa Empreender, em Uberlândia (MG).

Verificou-se que em relação à finalidade da utilização das informações contábeis gerenciais, os gestores informaram que são utilizadas principalmente para avaliar os impactos financeiros e acompanhar metas estabelecidas. Os gestores reconheceram a importância das informações gerenciais, indicando que muitas vezes não conseguem implementá-las por falta de conhecimento, ou seja, não possuem qualificação na área de negócios.

Verificou-se que as ferramentas gerenciais apontadas como mais utilizadas pelos gestores foram o fluxo de caixa, complementado com o controle de contas a pagar e a receber, resultados similares aos achados do estudo realizado por Albuquerque et al. (2013).

Quanto à frequência de utilização das informações gerenciais, não foi possível identificar formalmente a periodicidade de utilização, os gestores não 
mantém uma frequência de utilização de relatórios gerenciais para embasar as decisões nas MPEs.

$\mathrm{Na}$ etapa quantitativa do estudo, foi possível analisar um número maior de gestores e observou-se, dentre as ferramentas gerenciais apresentadas, que a maioria é considerada de grande utilidade para as decisões gerenciais. Quanto a frequência de utilização, percentuais relevantes indicaram "muito utilizadas" para os controles indicados. Em contrapartida, as ferramentas de gestão de ativo permanente, orçamento e controle de investimento, controle de sistema de informações gerenciais e do orçamento operacional, foram julgadas como "pouco utilizada".

$\mathrm{Na}$ etapa quantitativa, os resultados apresentam indícios que os gestores das pequenas empresas consideram importante às informações contábeis gerenciais e indicam que são utilizadas com frequência no processo de gestão da empresa. Nas entrevistas, foi possível aprofundar tal análise. Verificou-se que os gestores possuem dificuldades de utilizar as ferramentas gerencias e também de analisar as informações fornecidas pelos relatórios gerenciais.

Espera-se que os resultados deste estudo possam contribuir para que os gestores das MPEs confirmem a importância da implementação do uso das ferramentas de controle gerencial para a gestão de seu negócio, que tragam contribuições que evidenciem a aplicação prática de investigações envolvendo pequenas empresas e que possam complementar a literatura sobre a temática. Além disto, espera-se colaborar com o programa empreender, visto que a pesquisa pode contribuir para a elaboração de ações/estratégias para implementação das ferramentas de controle gerencial.

Por fim, é importante apresentar a limitação da presente pesquisa, no que se refere a uma pequena amostra de gestores de pequenas empresas, o que não permite a generalização dos resultados. Sugere-se para pesquisas futuras a replicação deste estudo em outras localidades para possíveis comparações com os resultados encontrados, além de aplicação em empresas que não participem do Programa Empreender a fim de verificar se há diferenças significativas entre os resultados encontrados.

BORGES, L. F. M.; LEAL, E. A. Utilidade da informação contábil gerencial na gestão das micro e pequenas empresas: um estudo com empresas do Programa Empreender de Uberlândia - MG. Revista de Empreendedorismo e Gestão de Pequenas Empresas, v.4, n.3, 2015. 


\section{Referências:}

ALBUQUERQUE, E. M. N.; CARDOSO, L. A.; CARMO FILHO, M. M.; CAVALCANTE, T. S. B.; SOUZA, W. A. R. O uso de indicadores e relatórios contábeis para tomada de decisão nas micro e pequenas empresas do Estado do Amazonas. Revista de Administração da FATEA, v. 6, n. 6, p. 6 - 21, 2013.

ALMEIDA, L. B.; CARNEIRO JÚNIOR, M.; PANHOCA, L.; SILVA, W. V. Uma investigação sobre importância e uso da informação gerencial nas empresas do Polo Gastronômico de Santa Felicidade, Curitiba [PR]. Revista de Estudos Contábeis, v. 4 , n. 6, p. $21-38,2013$.

ALVES, R. C.; ANTONIALLI, L. M.; LOPES, H. E. G.; SOUKI, G. Q.; REIS NETO, M. T. Estratégias "construídas" nas micro e pequenas empresas: um estudo no mercado central de Belo Horizonte. Revista da Micro e Pequena Empresa, v. 7, n. 3, p. 3-18, 2013.

ATKINSON, A. A.; BANKER, R. D.; KAPLAN, R. S.; YOUNG, S. M. Contabilidade gerencial. São Paulo: Atlas, 2000.

BARDIN, L. Análise de conteúdo. Tradução: Luís Antero Reto e Augusto Pinheiro. Lisboa: Edições 70, 2002.

BIASE, N. G.; FERREIRA, D. F. Comparações múltiplas e testes simultâneos para parâmetros binomiais de k populações independentes. Revista Brasileira de Biometria, v. 27, n. 3, p. 301-323, 2009.

BRASIL. Lei Complementar 139, de 10 de novembro de 2011. Dispõe sobre alteração, estatuto, microempresa, pequena empresa, regime especial, tributação, arrecadação, fiscalização, cobrança, unificação, impostos, contribuição social. Diário Oficial da União, Brasília, DF, 2011.

CHING, H. Y. Contabilidade Gerencial: novas práticas contábeis para a gestão de negócios. São Paulo: Pearson Prentice Hall, 2006.

CRESWELL, J. W. Projeto de Pesquisa: métodos qualitativo, quantitativo e misto. Porto Alegre: Artmed, 2007.

CUNHA, R. J.; ROCHA, E. L.; LEAL, E. A. A utilização e aplicabilidade da informação contábil pelos pequenos empresários da cidade de Uberlândia (MG) na percepção dos profissionais contábeis. In: CONGRESSO UFSC DE

BORGES, L. F. M.; LEAL, E. A. Utilidade da informação contábil gerencial na gestão das micro e pequenas empresas: um estudo com empresas do Programa Empreender de Uberlândia - MG. Revista de Empreendedorismo e Gestão de Pequenas Empresas, v.4, n.3, 2015. 
CONTROLADORIA E FINANÇAS \& INICIAÇÃO CIENTÍFICA, 2., 2008, Florianópolis. Anais... Florianópolis: UFSC, 2008. CD-ROM.

FARIA, J. A.; AZEVEDO, T. C.; OLIVEIRA, M. S. A utilização da contabilidade como ferramenta de apoio à gestão nas micro e pequenas empresas do ramo de comércio de material de construção de Feira de Santana/BA. Revista da Micro e Pequena Empresa, v. 6, n. 2, p. 89-106, 2012.

FENING, F. A.; PESAKOVIC, G.; AMARIA, P. Relationship between quality management practices and the performance of small and medium size enterprises (SMEs) in Ghana. International Journal of Quality \& Reliability Management, v. 25, n. 7, p. 694-708, 2008.

FERNADES, F. C.; KLANN, R. C.; FIGUEREDO, M. S. A utilidade da informação contábil para a tomada de decisões: uma pesquisa com gestores alunos. Contabilidade Vista \& Revista, v. 22, n. 3, p. 99-126, 2011.

FREZATTI, F.; AGUIAR, A. B.; GUERREIRO, R. Diferenciações entre a Contabilidade Financeira e a Contabilidade Gerencial: uma pesquisa empírica a partir de pesquisadores de vários países. In: ENCONTRO NACIONAL DE PÓSGRADUAÇÃO E PESQUISA EM ADMINISTRAÇÃO, 30., 2006, Salvador. Anais... Salvador: UFBA, 2006. CD-ROM.

GARRISON, R. H., NOREEN, E. W.; BREWER, P. C. Contabilidade gerencial. 11 ed. Rio de Janeiro: LTC, 2007.

HORNGREN, C. T.; SUNDEM, G. L.; STRATTON, W. O. Contabilidade gerencial. São Paulo: Prentice Hall, 2004.

HUANG, X. Strategic decision making in Chinese SMEs. Chinese Management Studies, v. 3, n. 2, p. 87-101, 2009.

HUTCHINSON, V.; QUINTAS, P. Do SMEs do knowledge management? Or simply manage what they know? International Small Business Journal, v. 26, n. 2, p. 131154, 2008.

MARTINS, G. de A.; THEÓPHILO, C. R. Metodologia da investigação científica para ciências sociais aplicadas. São Paulo: Atlas, 2007.

BORGES, L. F. M.; LEAL, E. A. Utilidade da informação contábil gerencial na gestão das micro e pequenas empresas: um estudo com empresas do Programa Empreender de Uberlândia - MG. Revista de Empreendedorismo e Gestão de Pequenas Empresas, v.4, n.3, 2015. 
MEGLIORINI, E.; RODRIGUES, R. N.; PEREIRA, A. C. Introdução à contabilidade gerencial. In: PARISI, C.; MEGLIORINI, E. (Org.). Contabilidade Gerencial. São Paulo: Atlas, 2011.

MIRANDA, L. C.; FREIRE, D. R.; SATURNINO, O. Demanda por Serviços Contábeis pelos Mercadinhos: são os Contadores Necessários? Contabilidade Vista \& Revista, v. 19, n. 1, p. 131-151, 2009.

MIZUMOTO, F. M. et al. O impacto de capital humano, capital social e práticas gerenciais na sobrevivência de empresas nascentes: um estudo com dados de pequenas empresas no Estado de São Paulo. Revista de Administração da USP, v. 45 , n. 4 , p. $343-355,2010$.

PELEIAS, I. R. Contabilidade gerencial em empresas de pequeno e médio porte. In: PARISI, C.; MEGLIORINI, E. (Org.). Contabilidade Gerencial. São Paulo: Atlas, 2011, p. 284-297.

SANDBERG, W. R.; ROBINSON, R. B.; PEARCE II, J. A. Why small businesses need a strategic plan. Business and Economic Review, v. 48, n. 1, p. $12-15$, 2001.

SANTOS, J. J. Contabilidade e análise de custos: modelo contábil, métodos de depreciação, ABC - custeio baseado em atividades, análise atualizada de encargos sociais sobre salários. 5.ed. São Paulo: Atlas, 2009.

SAVIOZ, P.; BLUM, M.. Strategic forecast tool for SMEs: how the opportunity landscape interacts with business strategy to anticipate technological trends. Technovation, v. 22, n. 2, p. 91 - 100, 2002.

SEBRAE, Serviço Brasileiro de Apoio às Micros e Pequenas Empresas. Boletim estatístico de micro e pequenas empresas. Observatório Sebrae, $1^{\circ}$ semestre de 2005.

Pequenas empresas geram 52\% dos empregos no País. Disponível em: $<$ http://portal.rn.sebrae.com.br/noticia.php?id=115>. Acesso em: 28 ago. 2013a.

Critérios de classificação de empresas: EI - ME - EPP. Disponível em: $<$ http://www.sebrae-sc.com.br/leis/default.asp?vcdtexto=4154>. Acesso em: 10 set. 2013b.

BORGES, L. F. M.; LEAL, E. A. Utilidade da informação contábil gerencial na gestão das micro e pequenas empresas: um estudo com empresas do Programa Empreender de Uberlândia - MG. Revista de Empreendedorismo e Gestão de Pequenas Empresas, v.4, n.3, 2015. 
Sobrevivência das empresas no Brasil. Coleção de estudos e pesquisas

julho/2013. Disponível em: <http:// http://www.sebrae.com.br/Sebrae/Portal\%20Sebrae/Anexos/Sobrevivencia_das_em presas_no_Brasil=2013.pdf> Acesso em: 20 set. 2013c.

SELS, L. et al. Linking HRM and small business performance: an examination of the impact of HRM intensity on the productivity and financial performance of small businesses. Small Business Economics, v. 26, n.1, p. 83 - 101, 2006.

STROEHER, A. M.; FREITAS, H. O uso das informações contábeis na tomada de decisão em pequenas empresas. Revista de Administração Eletrônica RAUSP-e, v. 1 , n. 1, p. $1-25,2008$.

THORNHILL, S.; AMIT, R. Learning about failure: bankruptcy, firm age, and the resource-based view. Organization Science, v. 14, n. 5, p. 497 - 509, 2003.

VOGEL, J.; WOOD JUNIOR., T. Práticas gerenciais de pequenas empresas industriais do Estado de São Paulo: um estudo exploratório. Revista de Empreendedorismo e Gestão de Pequenas Empresas, v. 1, n. 2, p. 117 - 140, 2012.

BORGES, L. F. M.; LEAL, E. A. Utilidade da informação contábil gerencial na gestão das micro e pequenas empresas: um estudo com empresas do Programa Empreender de Uberlândia - MG. Revista de Empreendedorismo e Gestão de Pequenas Empresas, v.4, n.3, 2015. 